\title{
CONSUMO DE ÁGUA EM PLANTIOS DE EUCALIPTO: PARTE 2 MODELAGEM DA RESISTÊNCIA ESTOMÁTICA E ESTIMATIVA DA TRANSPIRAÇÃO EM TRATAMENTOS IRRIGADOS E NÃO-IRRIGADOS ${ }^{1}$
}

\author{
Rogério Lessa de Castro Carneiro ${ }^{2}$, Aristides Ribeiro ${ }^{3}$, Carlos Alberto Martinez y Huaman ${ }^{4}$, Fernando \\ Palha Leite ${ }^{5}$, Gilberto Chohaku Sediyama ${ }^{3}$ e Julio César Lima Neves ${ }^{6}$
}

\begin{abstract}
RESUMO - Este trabalho constitui a ultima parte do estudo que objetivou calcular o consumo de água em plantios de eucalipto. Nesta parte, modelou-se a resistência estomática em função das variáveis ambientais irradiância solar global, déficit de pressão de vapor e temperatura. Com a resistência estomática modelada a partir dos valores observados no artigo anterior, foi possível calcular a transpiração do eucalipto pelo método Penman-Monteith em alguns dias, nos períodos úmido e seco do ano. Verificou-se a existência da correlação entre a resistência estomática e as variáveis ambientais. Os modelos gerados nessa relação mostraram-se eficientes para calcular as variações diárias resistência estomática e também totais horários e diários de transpiração.
\end{abstract}

Palavras-chave: Modelagem, resistência estomática e eucalipto .

\section{WATER CONSUMPTION IN EUCALYPT PLANTATIONS: PART 2 - MODELING STOMATAL RESISTANCE AND ESTIMATING TRANPIRATION IN IRRIGATED AND NON-IRRIGATED TREATMENTS}

\begin{abstract}
This paper concludes the last part of the work aimed to calculate water consumption in eucalypt plantations. Stomatal resistance was modeled as a function of the following ambient variables: global solar irradiance, vapor pressure deficit and temperature. Based on stomatal resistance modeled from the values observed in the first part of this work, eucalypt transpiration by the Penman-Monteith method could be calculated in some days during the humid and dry periods of the year. Correlation between stomatal resistance and ambient variables was verified. The models generated by this relation proved efficient in calculating the diurnal variation of stomatal resistance as well as hourly and daily transpiration totals.
\end{abstract}

Keywords: Modeling, stomatal resistance and eucalypt.

\footnotetext{
${ }^{1}$ Recebido em 19.05.2006 e aceito para publicação em 15.12.2007.

${ }^{2}$ Instituto Nacional de Pesquisas Espaciais Cptec/Inpe. E-mail : <carneiro@cptec.inpe.br>.

${ }^{3}$ Departamentod e Engenharia Agrícola da Universidade Federal de Viçosa (UFV). E-mail: <ribeiro@ufv.br>e < sediyama@ufv.br>.

${ }^{4}$ Faculdade de Filosofia, Ciências e Letras de Ribeirão Preto,USP. E-mail: <carlosamh@ffclrp.usp.br>.

${ }^{5}$ Celulose-Nipo-Brasileira, CENIBRA. E-mail: < fernando.leite@cenibra.com.br>.

${ }^{6}$ Departamento de Solos da UFV. E-mail: <julio@solos.ufv.br>.
} 


\section{INTRODUÇÃO}

Reflorestamentos com árvores de eucalipto ainda são um assunto de polêmica no que diz respeito ao consumo de água e sua relação com a produtividade. $\mathrm{O}$ conhecimento das interações que ocorrem entre as condições ambientais e as trocas gasosas no dossel vegetal é essencial na determinação da quantidade de água transpirada por essas florestas. Devido à grande pressão que esse assunto provoca, os estudos relacionados vêm aumentando substancialmente durante as duas últimas décadas Whitehead e Hinckley (1991), Kaufmann e Linder (1996), Mielke et al. (1999), Gao (2000) e Soares e Almeida (2001).

A resistência imposta pela abertura do estômato para as trocas gasosas varia de acordo com o grau de abertura desse órgão. Fatores fisiológicos associados às condições ambientais controlam a intensidade dessa abertura e, conseqüentemente, a resistência estomática $\left(\mathrm{r}_{\mathrm{s}}\right)$, que é inversamente proporcional à condutância estomática $\left(\mathrm{g}_{\mathrm{s}}\right)$, objeto de discussão no artigo anterior, onde - sendo $\mathrm{r}_{\mathrm{s}}=\mathrm{g}_{\mathrm{s}}{ }_{\mathrm{s}}^{-1}$. No artigo anterior, observouse que as condições do ambiente influenciaram o processo de trocas gasosas. Dentre as variáveis ambientais analisadas, destacaram-se: irradiância solar global, temperatura, déficit de pressão de vapor e umidade solo. Muitos estudos foram realizados no sentido de quantificar a magnitude dos efeitos climáticos sobre o controle estomático nas trocas gasosas entre o dossel vegetal e a atmosfera, destacando-se os realizados por Hall et al. (1976), Sheriff (1979), Landsberg e Butller (1980), Ludlow (1980), Jarvis (1980), Whitehead et al. (1981), Schulze et al. (1987), Tenhunen et al. (1987), Mielke et al. (1999), Gao (2000), Soares e Almeida (2001), Thomas et al. (2006) e Souza (2005).

Existem várias metodologias para a estimativa da transpiração, dentre as quais se destacam os métodos combinados, que levam em consideração os efeitos do balanço de energia e a capacidade do ar em reter vapor de água. O método de Penman-Monteith (MONTEITH, 1965), além de considerar os dois efeitos citados, incorpora os efeitos da resistência à perda de vapor de água imposta pelo dossel vegetal nas trocas gasosas. A teoria do método supõe que o dossel vegetal é representado por uma única e enorme folha. Desse modo, a resistência estomática é um parâmetro do modelo para o cálculo da transpiração.
O conhecimento dos fatores que controlam a resistência do dossel em perder vapor de água é um importante fator para a modelagem dos processos realizados no sistema solo-planta-atmosfera. Dento do exposto, este trabalho objetivou a modelagem da resistência estomática em função da irradiância solar global, déficit de pressão de vapor e temperatura, pois essas variáveis podem ser facilmente medidas e exercem grande influência na resistência estomática. Também, objetivou-se o cálculo da transpiração da cultura de eucalipto pelo método de Penman-Monteith em plantios de eucalipto irrigado e não-irrigado.

\section{MATERIAL E MÉTODOS}

A partir dos valores da condutância estomática (artigo anterior), calculou-se a resistência estomática, a partir da qual se derivou um modelo matemático para simulação da variação da resistência estomática em função das variáveis ambientais irradiância solar global, déficit de pressão de vapor e temperatura do ar.

O cálculo do consumo de água pelo eucalipto foi realizado utilizando-se a equação de Penman-Monteith (equação 1), com valores calculados a cada 10 min e posteriormente integrados para valores horários e diários.

$\lambda E=\frac{s(R n-G)+M \rho_{a} c_{p} D P V / r_{a}}{s+\gamma\left(1+r_{s} / r_{a}\right)}$

em que $\boldsymbol{E}$ é a transpiração, $\mathrm{mm} 10^{-1} \mathrm{~min}^{-1}$; $s$ é a declividade da curva de pressão de saturação do ar à temperatura do ar $\boldsymbol{t}, \mathrm{kPa}^{\circ} \mathrm{C}^{-1} ; \boldsymbol{R} \boldsymbol{n}$ é o balanço de radiação, $\mathrm{MJ} \mathrm{m}^{-2}$ $10^{-1} \mathrm{~min}^{-1} ; \boldsymbol{G}$ é o fluxo de calor no solo, $\mathrm{MJ} \mathrm{m}^{-2} 10^{-1} \mathrm{~min}^{-1} ; \boldsymbol{M}$ é fator de ajuste de escala, 600 para $10^{-1} \mathrm{~min}^{-1}$; $\boldsymbol{\rho}_{\boldsymbol{a}}$ é a densidade média do ar, $\mathrm{kg} \mathrm{m}^{-3}$; $\boldsymbol{c}_{\boldsymbol{p}}$ é o calor específico do ar, $\mathrm{MJ} \mathrm{kg}^{-1}{ }^{\circ} \mathrm{C}^{-1} ; \boldsymbol{\lambda}$ é o calor latente de vaporização, $\mathrm{MJ} \mathrm{kg}^{-1} ; \boldsymbol{D P} \boldsymbol{V}$ é o déficit de pressão de vapor, $\mathrm{kPa}$; $\boldsymbol{\gamma}$ é a constante psicrométrica, $\mathrm{kPa}^{\circ} \mathrm{C}^{-1} ; \boldsymbol{r}_{\boldsymbol{a}}$ é a resistência aerodinâmica, $\mathrm{s} \mathrm{m}^{-1}$; e $\boldsymbol{r}_{s}$ é a resistência estomática, $\mathrm{s} \mathrm{m}^{-1}$.

A resistência aerodinâmica foi calculada empregandose a equação (2), proposta por Brutsaert (1982):

$r_{a}=\frac{\operatorname{Ln}[(Z m-d) / Z o m] \operatorname{Ln}[(Z e-d) / Z o e]}{k^{2} U z}$

em que $\boldsymbol{r}_{\boldsymbol{a}}$ é a resistência aerodinâmica, $\mathrm{s} \mathrm{m}^{-1} ; \boldsymbol{Z m}$ é altura de medida de $\boldsymbol{U z}, \mathrm{m} ; \boldsymbol{Z} \boldsymbol{e}$ é a altura de medida da umidade do ar, m; Zom é o comprimento da rugosidade 
para o transporte de momentun, Zom $=0,123 \mathrm{hc}$, m; Zoe é o comprimento de rugosidade para o transporte de vapor e calor sensível, $Z o e=0,1 \mathrm{Zom}, \mathrm{m}$; $\boldsymbol{d}$ é o deslocamento do plano zero, $d=0,62$ hc, m; $U z$ é a velocidade do vento à altura $\mathrm{z}, \mathrm{m} \mathrm{s}^{-1}$; $\boldsymbol{k}$ é a constante de von Karman $\approx 0,4$; e hc é a altura da cultura, $\mathrm{m}$.

O saldo de radiação foi estimado a partir da modelagem do balanço de ondas curtas e do balanço de ondas longas, como a seguir:

$$
R n=B O C+B O L
$$

em que $\boldsymbol{R} \boldsymbol{n}$ é o balanço de radiação, $\mathrm{MJ} \mathrm{m}^{-2} 10^{-1} \mathrm{~min}^{-1}$; BOC é o balanço de ondas curtas, $\mathrm{MJ} \mathrm{m}^{-2} 10^{-1} \mathrm{~min}^{-1}$; e $\boldsymbol{B O L}$ é o balanço de ondas longas, $\mathrm{MJ} \mathrm{m}^{-2} 10^{-1} \mathrm{~min}^{-1}$.

$$
B O C=R g^{*}(1-\alpha)
$$

em que $\boldsymbol{B O C}$ é o balanço de ondas curtas, MJ $\mathrm{m}^{-2} 10^{-1} \mathrm{~min}^{-1} ; \boldsymbol{R g}$ é a irradiância solar global, MJ $\mathrm{m}^{-2} 10^{-1} \mathrm{~min}^{-1}$; e $\boldsymbol{\alpha}$ é o albedo da cultura do eucalipto, adimensional.

O albedo $\boldsymbol{\alpha}$ foi obtido a partir das medições diretas da irradiância solar global incidente $\boldsymbol{R g}$ e da irradiância solar global refletida pelo dossel $\boldsymbol{R} \boldsymbol{r}$, em medidas realizadas durante as campanhas de coleta de dados, como descrito a seguir:

$$
\alpha=R r / R g
$$

Para a estimativa do balanço de ondas longas em
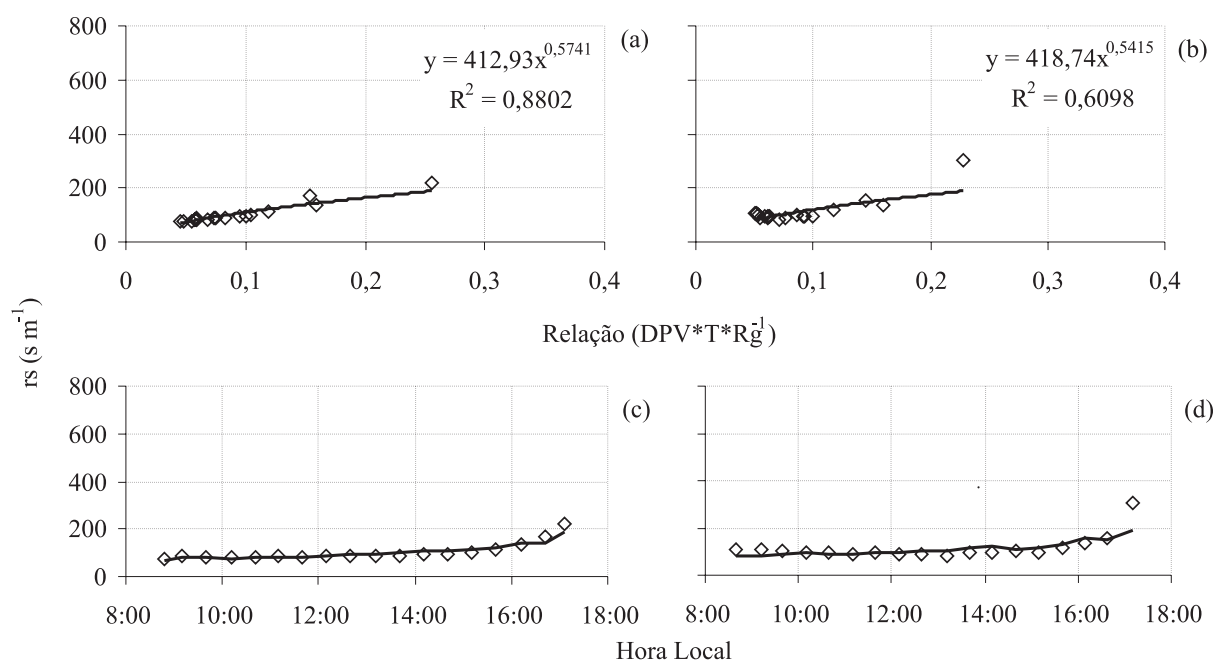

Figura 1 - Relação entre as variáveis ambientais (DPV.T.Rg ${ }^{-1}$ ) com a resistência estomática e o comportamento do modelo representado pelas linhas para com os valores reais representados pelos losangos, no período úmido, nos tratamentos irrigado (a e c) e não-irrigado (b e d) da primeira campanha.

Figure 1 - Relationship between the environmental variables $\left(D P V . T . \mathrm{Rg}^{-1}\right)$ and stomatal resistance and behavior of the linerepresented model in relation to the real lozenge-represented values in the humid period for the irrigated (a and c) and non-irrigated ( $b$ and d) treatments of the first series. plantios de eucalipto, utilizou-se a equação (6), proposta por Facco (2004).

$B O L=9,5035 * 10^{-5} * t^{4} *(0,09 * \sqrt{e}-0,56)+0,456$

em que $\boldsymbol{B O L}$ é o balanço de onda longa, $\mathrm{MJ} \mathrm{m}^{-2} 10^{-1} \mathrm{~min}^{-}$ ${ }^{1}$; $\boldsymbol{t}$ é a temperatura, ${ }^{\circ} \mathrm{C}$; e $\boldsymbol{e}$ é a pressão real de vapor, $\mathrm{mmHg}$.

O Índice de Área Foliar (IAF) foi medido na altura do solo em cada um dos dois tratamentos com o medidor de índice de área foliar LAI2000 (Licor, Lincoln, Nebraska, USA), para o cálculo da resistência imposta pelo dossel vegetal a partir da resistência estomática. A resistência do dossel foi obtida a partir dos valores da resistência estomática calculados pelos modelos matemáticos propostos e do IAF.

\section{RESULTADOS E DISCUSSÃO}

\subsection{Modelagem da resistência estomática}

As Figuras 1, 2 e 3 ilustram a relação matemática do produto das variáveis ambientais Irradiância Solar Global (Rg), Déficit de Pressão de Vapor (DPV) e Temperatura (T) com a resistência estomática. Também ilustram a comparação entre os valores médios horários observados e os gerados pelos modelos em todas as campanhas. No Quadro 1, apresentam-se somente as equações matemáticas e os coeficientes de correlação com os valores observados com os valores modelados em cada campanha e tratamento.

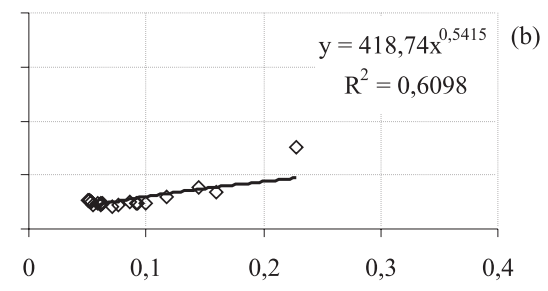

d)

R. Árvore, Viçosa-MG, v.32, n.1, p.11-18, 2008 


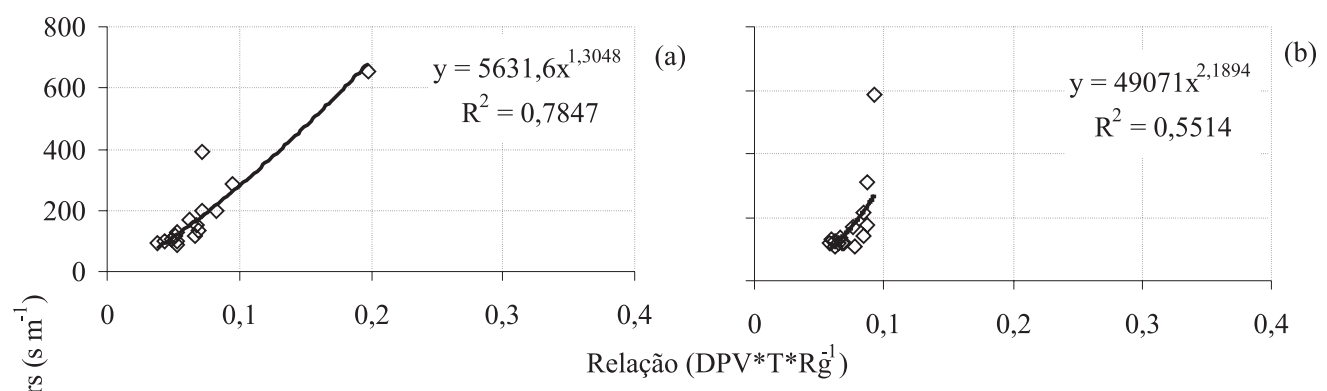

(b)

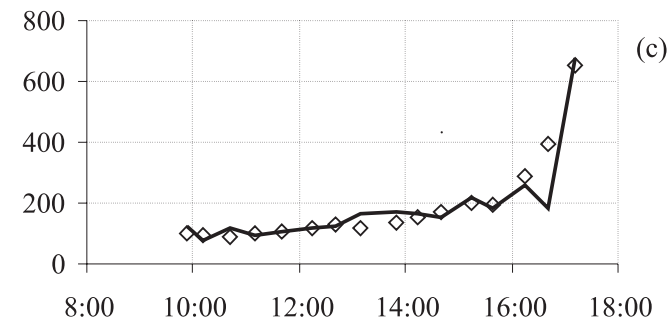

(c)

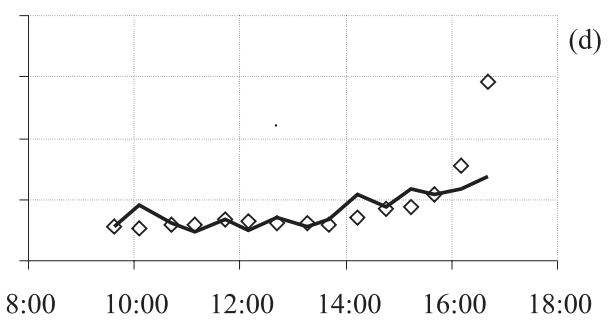

Hora Local

Figura 2 - Relação entre as variáveis ambientais (DPV.T. $\mathrm{Rg}^{-1}$ ) com a resistência estomática e o comportamento do modelo representado pelas linhas para com os valores reais representados pelos losangos, no início do período seco, nos tratamentos irrigado (a e c) e não-irrigado (b e d) da segunda campanha.

Figure 2 - Relationship between the environmental variables (DPV.T.R $\mathrm{g}^{-1}$ ) and stomatal resistance and the behavior of the line-represented model in relation to the real lozenge-represented values during the early dry period for the irrigated ( $a$ and $c$ ) and non-irrigated ( $b$ and $d$ ) treatments of the second series.
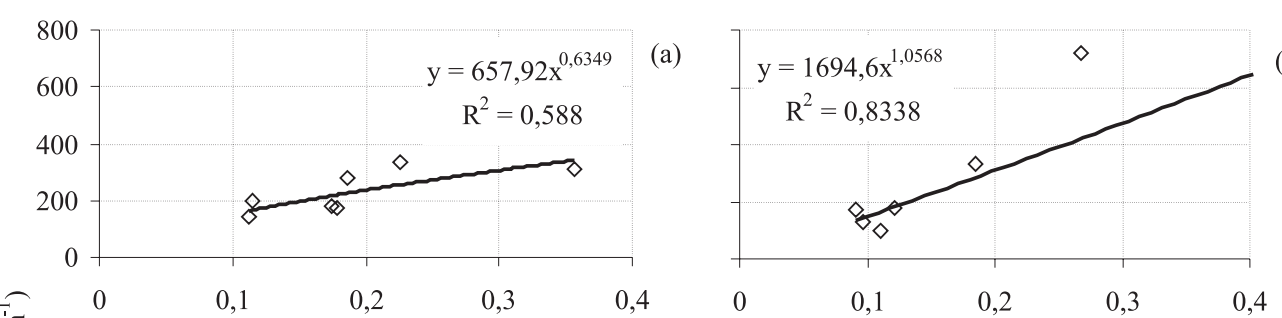

(b)

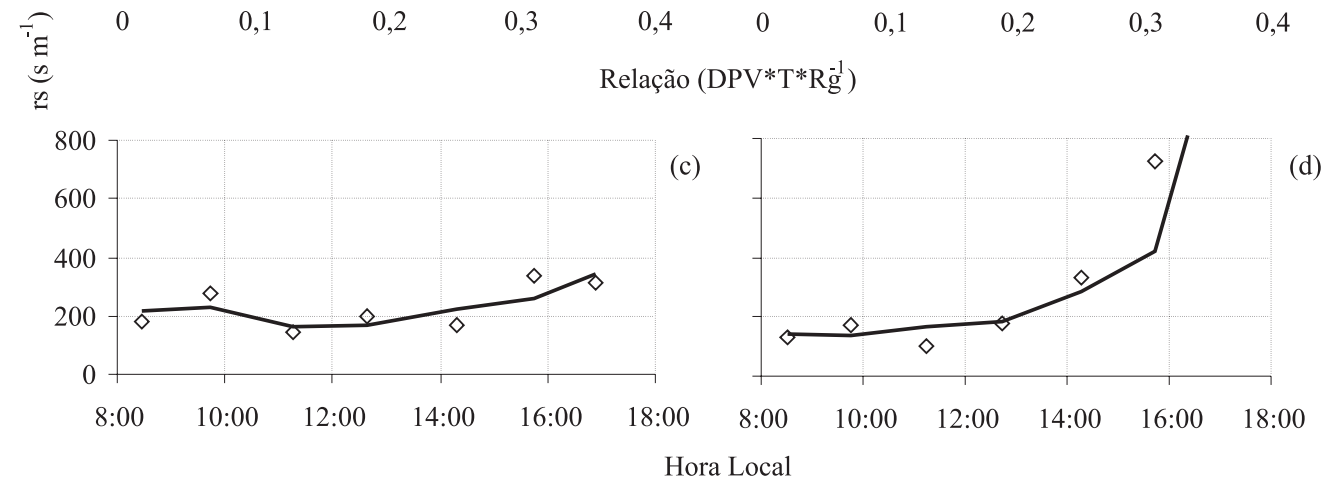

Figura 3 - Relação entre as variáveis ambientais (DPV.T.Rg ${ }^{-1}$ ) com a resistência estomática e o comportamento do modelo representado pelas linhas para com os valores reais representados pelos losangos, no período seco, nos tratamentos irrigado (a e c) e não-irrigado (b e d) da terceira campanha.

Figure 3 - Relationship between the environmental variables (DPV.T.R $\mathrm{R}^{-1}$ ) and stomatal resistance and the behavior of the line-represented model for the real lozenge-represented values during the dry period for the irrigated (a and $c)$ and non-irrigated ( $b$ and d) treatments of the third series.

R. Árvore, Viçosa-MG, v.32, n.1, p.11-18, 2008 
Quadro 1 - Equações provenientes da modelagem da resistência estomática ( $\mathrm{r}_{\mathrm{s}}$ ) das três campanhas (C1, C2 e C3) e tratamentos irrigado (IR) e não irrigado (NI), com os parâmetros, déficit de pressão de vapor (DPV) em kPa, temperatura (T) em ${ }^{\circ} \mathrm{C}$ e irradiância solar global (Rg) em $\mathrm{W} \mathrm{m} \mathrm{m}^{-2}$

Table 1 - Equations originated from stomatal resistance modeling $\left(r_{s}\right)$ for the three series (C1, C2 and C3) and irrigated (IR) and non-irrigated treatments (NI) with the parameters vapor pressure deficit (DPV) in kPa, temperature (T) in ${ }^{\circ} \mathrm{C}$ and global solar irradiance $(\mathrm{Rg})$ in $\mathrm{W} \mathrm{m}^{-2}$

\begin{tabular}{cccc}
\hline Tratamento & Campanha & Equação & $\mathrm{r}^{2}$ \\
\hline IR & C1 & $\mathrm{r}_{\mathrm{s}}=412,93\left(\mathrm{DPV}^{*} \mathrm{~T} \mathrm{Rg}^{-1}\right)^{0,5741}$ & 0,88 \\
NI & $\mathrm{C} 1$ & $\mathrm{r}_{\mathrm{s}}=418,74(\mathrm{DPV} \mathrm{T} \mathrm{Rg})^{0,5415}$ & 0,61 \\
IR & $\mathrm{C} 2$ & $\left.\mathrm{r}_{\mathrm{s}}=5631,60(\mathrm{DPV} \mathrm{T} \mathrm{Rg})^{-1}\right)^{1,1348}$ & 0,78 \\
NI & $\mathrm{C} 2$ & $\mathrm{r}_{\mathrm{s}}=4907,00(\mathrm{DPV} \mathrm{T} \mathrm{Rg}$ & \\
IR & $\mathrm{C} 3$ & $\mathrm{r}_{\mathrm{s}}=657,92(\mathrm{DPV} \mathrm{T} \mathrm{Rg})^{-1,1804}$ & 0,55 \\
NI & $\mathrm{C} 3$ & $\mathrm{r}_{\mathrm{s}}=1694,6\left(\mathrm{DPV} \mathrm{T} \mathrm{Rg} \mathrm{Rg}^{-1}\right)^{1.0568}$ & 0,59 \\
N & & & 0,83 \\
\hline
\end{tabular}

Verificou-se a existência de uma correlação entre os valores da resistência estomática e o produto das variáveis ambientais (DPV.T. Rg ${ }^{-1}$ ) (Figuras 1ab, 2ab e 3ab). Algumas campanhas como C1_IR, C2_IR e C3_NI obtiveram bons coeficientes de correlação, variando de 0,78 a 0,88 , porém com os valores de outras não foram conseguidos resultados tão bons. Contudo, a relação ruim nas outras campanhas pode ser explicada pela umidade do solo, que é um fator que tem grande influência na resistência estomática, mas que não foi considerada. Isso se deve ao fato de que a umidade do solo não foi amostrada com a mesma freqüência com que foram medidos os valores da condutância estomática. Assim, a amostragem da umidade do solo não foi suficiente para determinar a variação da umidade do solo na escala de um dia. Dessa maneira, a utilização da umidade do solo como parâmetro nos modelos apenas mascarou a relação entre as outras variáveis ambientais. Por esse motivo, a umidade do solo foi desconsiderada. Acredita-se que um monitoramento mais ostensivo da umidade do solo possa melhorar a resposta do modelo às variáveis ambientais, mas isso não pôde ser demonstrado neste trabalho.

\subsection{Estimativa da transpiração}

Utilizaram-se os modelos de resistência estomática obtidos nos períodos úmido e seco, pois esses períodos apresentaram variação significativa na condutância estomática entre as campanhas (ver Quadro 6 do artigo anterior). Calculou-se o consumo médio horário diário de água nos tratamentos irrigado e não-irrigado nesses períodos, utilizando a equação de Penman-Monteith.

Na simulação realizada para o período úmido foram observados totais horários máximos de transpiração de $0,19 \mathrm{~mm} \mathrm{~h}^{-1}$ no tratamento irrigado e de $0,17 \mathrm{~mm} \mathrm{~h}^{-1}$ no tratamento não-irrigado. Os valores médios e os respectivos desvios-padrão podem ser vistos na Figura 4ab. Os totais diários máximos da transpiração foram de $8,60 \mathrm{~mm} \mathrm{~d}^{-1}$ e $6,17 \mathrm{~mm} \mathrm{~d}^{-1}$ nos tratamentos irrigado e não-irrigado, respectivamente (Figuras 4cd). No período seco do ano (Figura 5), os totais máximos horários foram maiores do que os verificados no período úmido, no entanto com os totais diários sendo menores. Esse fato se deve aos maiores valores de condutância estomática observados na terceira campanha, no tratamento não-irrigado, porém as variáveis ambientais no período de simulação foram menos favoráveis à transpiração nesse período, refletindo, assim, nos totais diários modelados.

Devido aos altos coeficientes de correlação obtidos nas equações geradas para simular a resistência estomática, acredita-se que a estimativa da transpiração tenha confiabilidade satisfatória. Valores de transpiração apresentados em outros trabalhos indicaram coerência com os mostrados nas Figuras 4 e 5. Sacramento Neto (2001) encontrou valores variando de 8,60 a $1,00 \mathrm{~mm} \mathrm{~d}^{-1}$ no eucalipto com 2 anos de idade, na mesma região.

Mielke et al. (1999) obtiveram, em plantações de 9 anos de idade, valores médios de $0,50 \mathrm{~mm} \mathrm{~h}^{-1} \mathrm{em}$ março, o que compreende aproximadamente $6,0 \mathrm{~mm} \mathrm{~d}^{-1}, 0,40$ $\mathrm{mm} \mathrm{h}^{-1} \mathrm{em}$ abril, correspondemdo a cerca de $4,8 \mathrm{~mm}$ $\mathrm{d}^{-1} \mathrm{e}, 0,20 \mathrm{~mm} \mathrm{~h}^{-1} \mathrm{em}$ agosto, o que equivale aproximadamente a $2,40 \mathrm{~mm} \mathrm{~d}^{-1}$. Dye (1987) encontrou valores variando de 2,40 a 8,6 mm d-1 em árvores de Eucalyptus grandis com 22 m de altura. Dunin e Mackay (1982) observaram valores médios mensais variando de 0,12 a $6,80 \mathrm{~mm} \mathrm{~d}^{-1}$, em Eucalyptus maculata com idade entre 7 e 9 anos.

R. Árvore, Viçosa-MG, v.32, n.1, p.11-18, 2008 


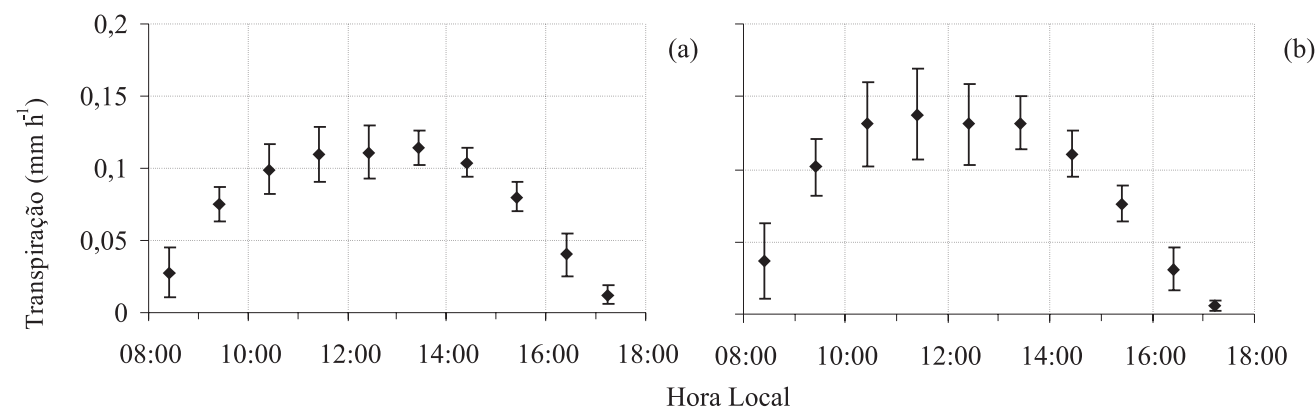

(b)
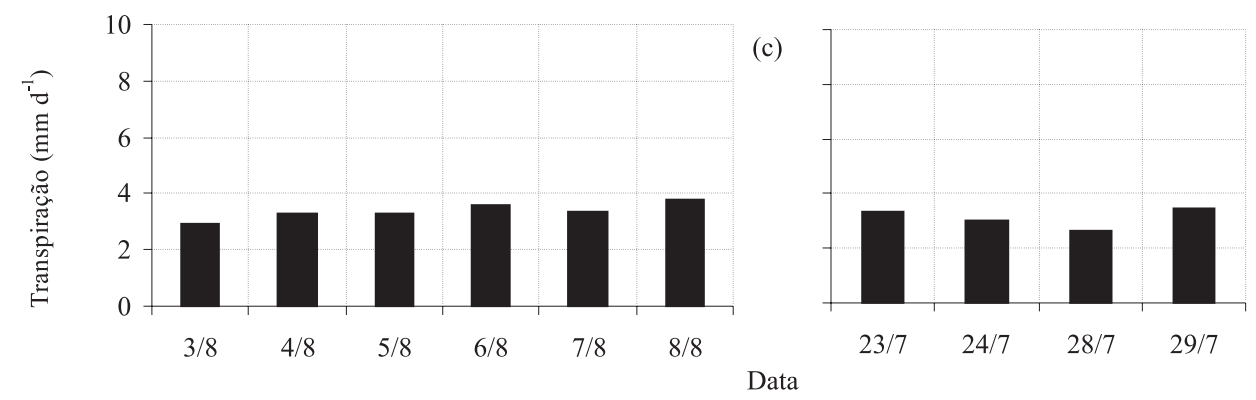

(d)

Figura 4 - Estimativa da transpiração horária e transpiração total diária nos tratamentos irrigado (a e c) e não-irrigado (b e d) no período úmido.

Figure 4-Estimate of the hourly and total daily transpiration in the irrigated ( $a$ and $c$ ) and non-irrigated ( $b$ and d) treatments for the humid period.
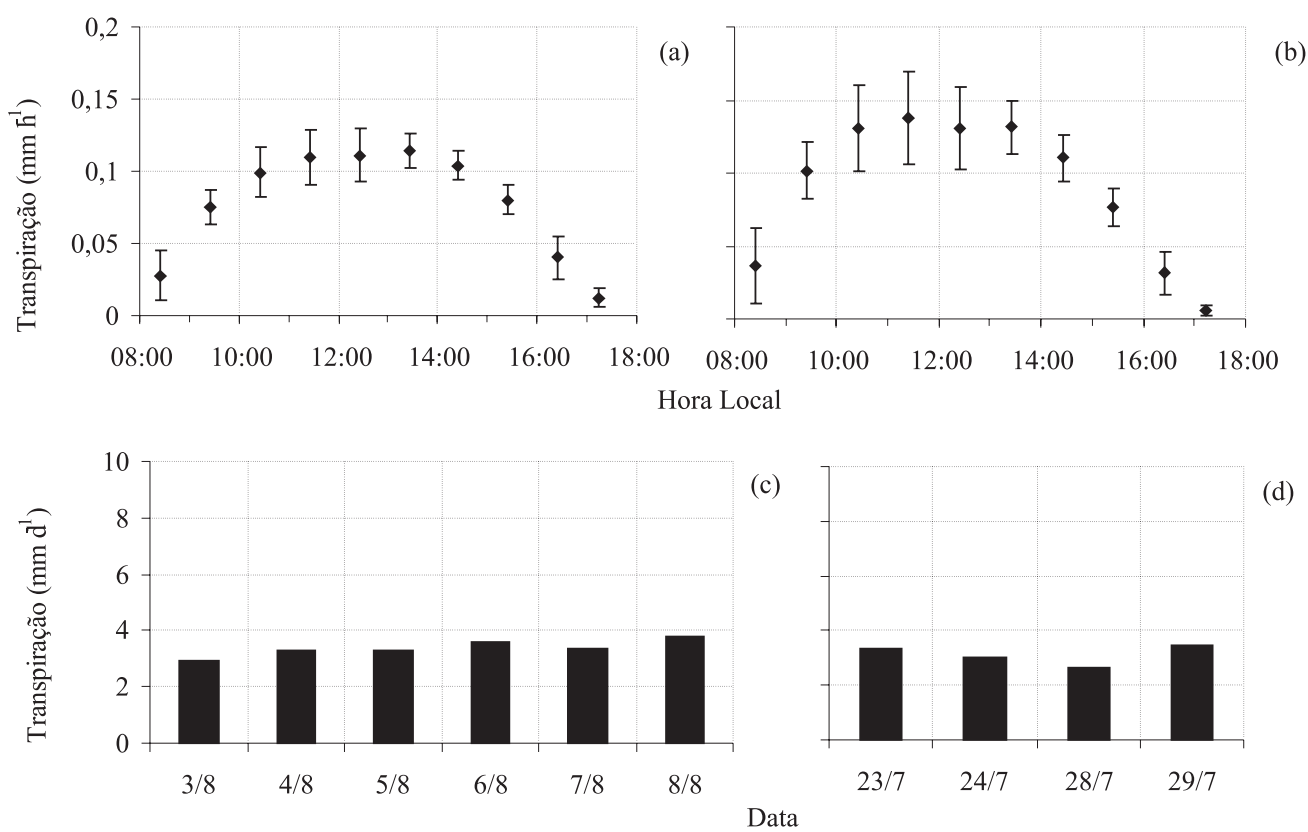

(d)

Figura 5 - Estimativa da transpiração horária e total diária nos tratamentos irrigado (a e c) e não-irrigado (b e d) no período seco.

Figure 5 - Estimate of the hourly and total daily transpirations in the irrigated ( $a$ and $c$ ) and non-irrigated (b and d) treatments during the dry period.

R. Árvore, Viçosa-MG, v.32, n.1, p.11-18, 2008 


\section{CONCLUSÕES}

Verificou-se a existência da correlação entre a resistência estomática e as variáveis ambientais: irradiância solar global, déficit de pressão de vapor de água e temperatura. Os modelos gerados baseados nessa relação mostraram-se simulares à resistência estomática e, consequentemente, aos totais horários e diários de transpiração.

\section{AGRADECIMENTOS}

À Coordenação de Aperfeiçoamento de Pessoal de Nível Superior (CAPES), pelo financiamento desta pesquisa; e à empresa florestal Celulose Nipo-Brasileira (CENIBRA), pelos apoios financeiro, logístico e de recursos humanos.

\section{REFERÊNCIAS}

BRUTSAERT, W. Evaporation into the atmosphere. Boston: D. Reidel, 1982. 299p.

DUNIN, F. X.; MACKAY, S. M. Evaporation by euvalypt and Ciniferous foreste communities. In: NATIONAL SYMPOSIUN ON FOREST HYDROLOGY, 1., 1982, Melbourne. Preprints... Melbourne: The Instituton of Enginners, 1982. p.12-17. (National Conference Publication, 82/6)

DYE, P. J. Estimating water use by Eucalyptus grandis wich Penman-Monteith equation. In: VANCOUVER SYNPOSIUM FOREST HIDROLOGY AND WATERSHED MANANEGENT, 1987, Vancouver. Proceedings... Vancouver: International Association of Hidrological Sciences, 1987. p.329-337.

FACCO, A. G. Modelagem e simulação geoespacial dos componentes do balanço hídrico para plantios de eucaliptos em áreas de relevo

ondulado. 2004. 87f. Dissertação (Mestrado em Meteorologia Agrícola) - Universidade Federal de Viçosa, Viçosa, MG, 2004.

GAO, F. Water relations and gas exchange of tropical sapling during a prolonged drought in a Bornean heath forest, with reference to root architecture. Journal of Tropical Ecology, v.16, p.101-116, 2000.
HALL. A. E.; SCHULZE, E. D.; CHIPPENDALE, G. $M$. Current perspectives of steady-state stomatal responses to environment. In: LANGE, O. L. et al. (Eds.). Water and plant life. Berlin: Springer-Verlag, 1976. p.169-188.

JARVIS, P. G. Stomatal response to water stress in Conifers. In: TURNER, N. C.; KRAMER, P. J. (Eds.) Adaptation of plants to water and righ temperature stress. New York: John-Wiley, 1980. p.105-122.

KAUFMANN, M. R.; LINDER, S. Tree physiology in a changing word. Tree Physiology, v.16, n.1, p.1-4, 1996.

LANDSBERG, J. J.; BUTLER, D. R. Stomatal response to humidity: Implications for transpiration. Plant, Cells and Environment, v.3, n.1, p.29-33, 1980.

LUDLOW, M. M. Adaptative significanse of stomatal responses to water stress. In: WILSON, E. O. (Ed.) Adaptation of plants to water and righ temperature stress. New York: John-Wiley, 1980. p.123-138.

MONTEITH, J. L. Evaporation and environment. Symposium of the Society for Experimental Biology, v.19, p.205-234, 1965.

MIELKE, M. S. et al. Stomatal control of transpiration in the canopy of clonal Eucalyptus grandis plantation. Trees, v.13, n.1, p.152-160, 1999.

SACRAMENTO NETO, O. B. Balanço hídrico em plantios jovens de eucalipto na região de Belo OrienteMG. 2001. 77f. Dissertação (Mestrado em Meteorologia Agrícola) - Universidade Federal de Viçosa, Viçosa, MG, 2001.

SCHULZE, E. D. et al. Stomatal responses to air humidity and to soil drought. In: ZEIGER, E. et al. (Eds.). Stomatal function. Stanford: Stanford University Press, 1987. p.311-321.

SHERIFF, D. W. Stomatal aperture the sensing of the environment by guards cells. Plant, Cells and Environment, v.2, n.1, p.15-22, 1979.

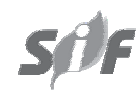

R. Árvore, Viçosa-MG, v.32, n.1, p.11-18, 2008 
SOARES, J. V.; ALMEIDA, A. C. Modeling the water balance and soil water fluxes in a fast growing Eucalyptus plantation Brazil. Journal of Hidrology, v.253, n.1/4, p.130-147, 2001.

SOUZA, M. H. et al. Disponibilidade hídrica do solo e produtividade do eucalipto em três regiões da bacia do Rio Doce. Revista Árvore, v.30, n.3, p.399-410, 2005.

TENHUNEN, J. D.; PEARCY, R. W.; LANGE, O. L. Diurnal variation in leaf condutance and gas exchange in natural environments In: ZEIGER, E. et al. (Eds.). Stomatal function. Stanford: Stanford University Press, 1987. p.323-351.
THOMAS, D. S.; MONTAGU, K. D.; CONROY, J. P. Effects of leaf and branch removal on carbon assimilation and stem wood density of Eucalyptus grandis seedlings. Trees, v.20, p.725-733, 2006.

WHITEHEAD, D.; OKALI, D. U. U.; FASEHUN, F. E. Stomatal response to environmental variables in two tropical species during the dry season in Nigeria. Journal of Applied Ecology, v.18, n.2, p.571-587, 1981.

WHITEHEAD, D.; HINCKLEY, T. M. Models of water flux through forest stands: Critical leaf and stand parameters. Tree Physiology, v.18, p.571-587, 1991. 